\title{
A Blueprint for Schoolwide Positive Behavior Support: Implementation of Three Components
}

\author{
ANN TURNBULL, HANK \\ EDMONSON, PETER GRIGGS, \\ DONNA WICKHAM, WAYNE \\ SAILOR, RACHEL FREEMAN, \\ DOUG GUESS, STEVE LASSEN, \\ AMY MCCART, JIYEON PARK, \\ LAURA RIFFEL, RUD TURNBULL, \\ JARED WARREN, \\ The University of Kansas
}

\begin{abstract}
This article provides a case study (focus on an eighth grader with autism) within a case study (focus on an urban middle school) in terms of the implementation of positive behavior support (PBS). Information is provided on the characteristics of three key components of schoolwide PBS -universal support, group support, and individual support. For each component information is presented on policy, assessment, and intervention in terms of an evolving approach to schoolwide PBS with descriptions of how the components were implemented at the middle school with a particular emphasis on the eighth grade student. The authors conclude with implications for practice in terms of assessing current resources, providing professional development, and intensifying universal support within urban schools to address some of the complex issues associated with poverty.
\end{abstract}

Positive behavior support (PBS) is a broad range of systemic and individualized strategies for achieving important social and learning outcomes while preventing problem behavior. PBS's key attributes include proactivity, databased decision making, and a problem-solving orientation (Horner, 2000; Lewis \& Sugai 1999; Sugai, et al., 2000; Weigle, 1997). As an extension of applied behavior analysis,
PBS does not have a sole and discrete focus of remediating a student's inappropriate behavior in a clinical setting through the expertise of a clinician using a functional analysis. Rather, PBS emphasizes a lifestyle focus in natural settings implemented by teachers, families, and perhaps others, using an array of assessment and support procedures (Carr et al., 1999; Turnbull 
\& Turnbull, 1999). A key focus of PBS is building responsive environments that "stack the deck" in favor of appropriate student behavior and preferred quality of life outcomes.

Research on PBS is in the process of evolving toward a focus on schoolwide and systemwide models. The OSEP National Technical Assistance Center on Positive Behavioral Supports and Interventions characterizes schoolwide PBS as having three components including (a) universal support, (b) group support, and (c) individual support (Horner, 2000; Lewis \& Sugai, 1999; Sugai et al., 2000). These components exist on two continua. The first is a continuum of scope of students involved. For example, universal support is provided to all students, while the next two components are provided to a decreasing number of students (see Figure 1). The second continuum is intensity, which refers to the strength of support for each student. Universal support is the least intense component, and each of the next two components is increasingly more intense in terms of the support that is provided (see Figure 1). Based on data provided by Horner and colleagues (R. H. Horner, personal communication, June 12, 2001), $76 \%$ of the students from 26 middle schools $(15,713$ students) received zero or one office discipline referral during the school year (students without serious problem behavior), $15 \%$ received two to five office referrals (students at risk), and 9\% received six or more office referrals (students with intense problem behavior), as illustrated in Figure 2 (left triangle). Generally, this translates into the general percentages of students who will require universal, group, and individual support.

In order for schoolwide PBS to be fully implemented, each of these three components should be addressed, and all students who require support within each component should be receiving the appropriate degree of intensity. In our experience, some people frequently interchange the concepts of schoolwide and universal support, implying that a schoolwide model only involves universal support. To the contrary, meeting the needs of all students requires a scope and intensity continua ranging from providing positive support to address the least intensive behaviors of all students to providing supports needed to address the most intensive behaviors of a more limited number of students.

This article describes a case study within a case study (Yin, 1994). The larger case study is a description of an emerging model of schoolwide PBS through ongoing work we are conducting in partnership with Central Middle School, an inner-city school in the Kansas City, Kansas, school district. Central educates approximately 762 students who attend sixth through eighth grades and is located in the heart of Kansas City, Kansas, in Wyandotte County. This county has the second-lowest graduation rate in the state $(68 \%)$, the highest percentage of children in poverty in the state $(32 \%)$, and the third highest number of childhood deaths in the state (Kansas Kids Count, 2000). Central reported 26.8 violent acts (i.e., malicious acts that result in out of school suspension or expulsion) against other students per 100 students compared with the district average of 9.5 and the state average of 4.9. Against staff, Central reported 2.2 violent acts per 100 students compared to the district's average of 1.0 and the state's 0.4 average per 100 students. In contrast to the normative percentages of students demonstrating various ranges of problem behavior (Sugai, Horner, \& Gresham, in press) as illustrated in Figure 2 (left triangle), the right triangle in Figure 2 depicts the percentages at Central. It is obvious that some of the special challenges in urban schools create a less responsive context for implementing schoolwide PBS (Warren et al., in press a and b).

The embedded case study within the larger school context focuses on an individual student, Jeremy Jones. Jeremy has autism and receives PBS support at Central across each of the three components. Jeremy is a 14-year-old AfricanAmerican eighth-grader. He likes to go to school and is quite skillful in spelling and readily learns factual information. Jeremy learns best in school environments that are structured, predictable in terms of behavioral expectations, and quiet, and that permit him to work in small groups with easy access to the teacher's attention. He is strongly motivated by enthusiastic and genuine praise, deep/firm pats on his shoulders and back, and special privileges. Jeremy's ability to focus his attention effectively on assigned tasks and activities 
FIGURE I

Continua of Scope and Intensity of Support in Schoolwide PBS

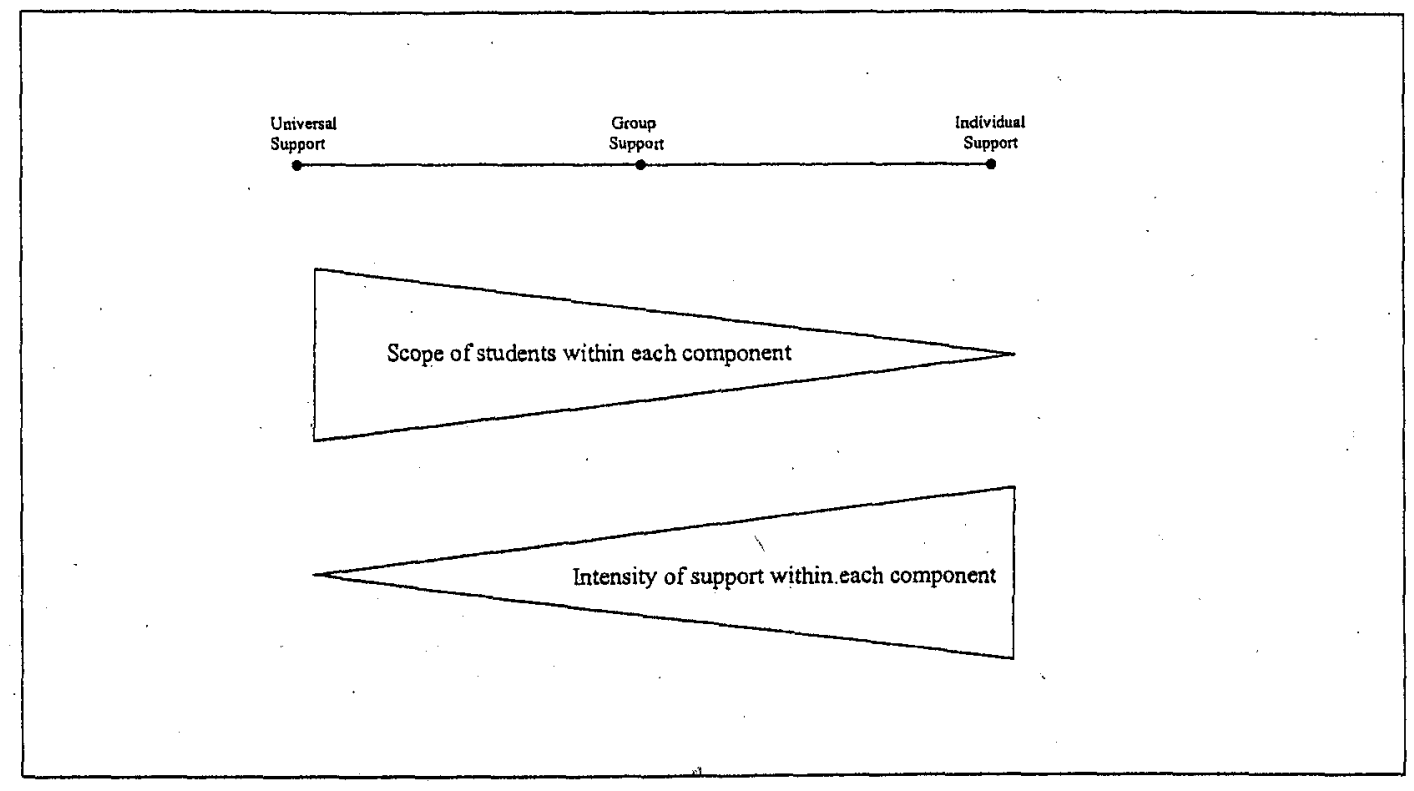

FIGURE 2

Percentages of Problem Behavior in "Typical" Schools and at Central Middle School

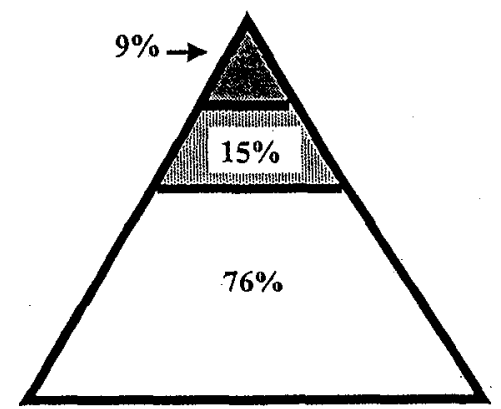

"Typical" Schools

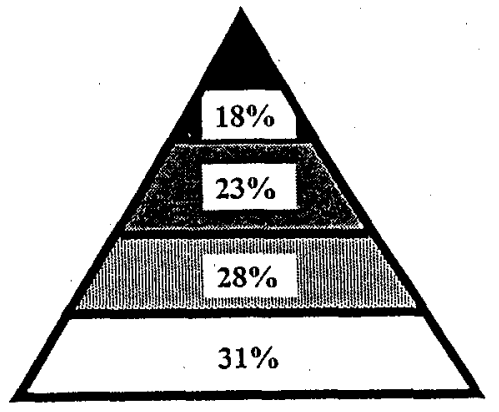

Central Middle School

- Students with Extreme Problem Behavior

Students with Chronic/Intense Problem Behavior

Students At-Risk for Problem Behavior

$\square$ Students without Serious Problem Behavior 
is significantly impeded. In addition, because Jeremy prefers to be by himself (e.g., eating lunch, "hanging out" before school begins), he seldom makes friends and has a very limited peer/social network. He has not yet acquired the critical social-communicative skills necessary to gain teacher and peer attention appropriately, as well as to communicate the need to avoid or lessen instructional demands or modify unpleasant and nonpreferred learning situations in socially acceptable ways.

We will describe the continua of scope and intensity for each of the three components at the school level and with particular emphasis on how the support impacted Jeremy. For each component, we address variations in policy, assessment, and interventions (i.e., antecedents, skills, consequences ). Table 1 provides a summary of this information. Data on the effectiveness of the schoolwide PBS in terms of student discipline is included, and the article concludes with implications for practice in terms of how schools who currently are not implementing schoolwide PBS can move in this direction.

\section{UNIVERSAL SUPPORT}

\section{OVERVIEW}

In terms of scope, universal support is taught directly to all students in a wide range of school settings (e.g., classrooms, hallways, playground, cafeteria, and library). Universal support is proactive in that every student gets effective PBS without identification or referral for specific problem behavior.

The goal of universal support is to significantly reduce or eliminate as many problem behaviors and increase as many appropriate behaviors as possible for as many students in the school as possible. Even students who require the most intensive PBS (i.e., individual support) for some of their problem behaviors still engage in some behaviors that can be adequately addressed through universal support.

The policy foundation for universal support is Title IV of the Improving America's Schools Act of 1994, the Safe and Drug-Free Schools and Communities Act, (1994). This Act authorizes the
Safe and Drug-Free Schools Program to develop violence and drug prevention programs through state and local education agencies. The Safe and Drug-Free Schools and Communities Act has been a catalyst for zero tolerance for drugs and guns. In order to preserve classroom safety, certain behaviors by students (e.g., use or sale of drugs or carrying of dangerous weapons) are immediate grounds for suspension or expulsion due to the danger they pose to other students and school personnel and to the vital interest of schools to maintain safe learning environments. Zero tolerance is supported in instances of (a) drug possession/use, and (b) carrying or possessing weapons by the Individuals with Disabilities Education Act (20 U.S.C. 1415 (k), [1999]).

Regarding assessment, the nature of data collection in universal support typically involves interviewing school staff and directly observing students across all school settings to determine the nature and extent of problem behavior. Additionally, major emphasis is given to tracking data on office discipline referrals, in-school suspensions, expulsions, detentions, and other forms of consequences that are typically used "across the board" in responding to problem behavior. In addition, other outcomes such as attendance, grades, and standardized test scores are monitored as universal support may have direct and indirect influence on these outcomes. These data become a means of monitoring schoolwide progress in terms of whether students, as a whole student body, are moving in a positive or negative direction. Based on these data, school staff develop hypotheses related to the antecedent factors and skill deficits associated with problem behavior. These hypotheses, in turn, then form the basis for developing universal support for schoolwide implementation.

Universal support is proactive in that every student gets effective PBS without identification or referral for specific problem behavior. 
TABLE 1

Summary of Key Features of Three Components of Schoolwide PBS

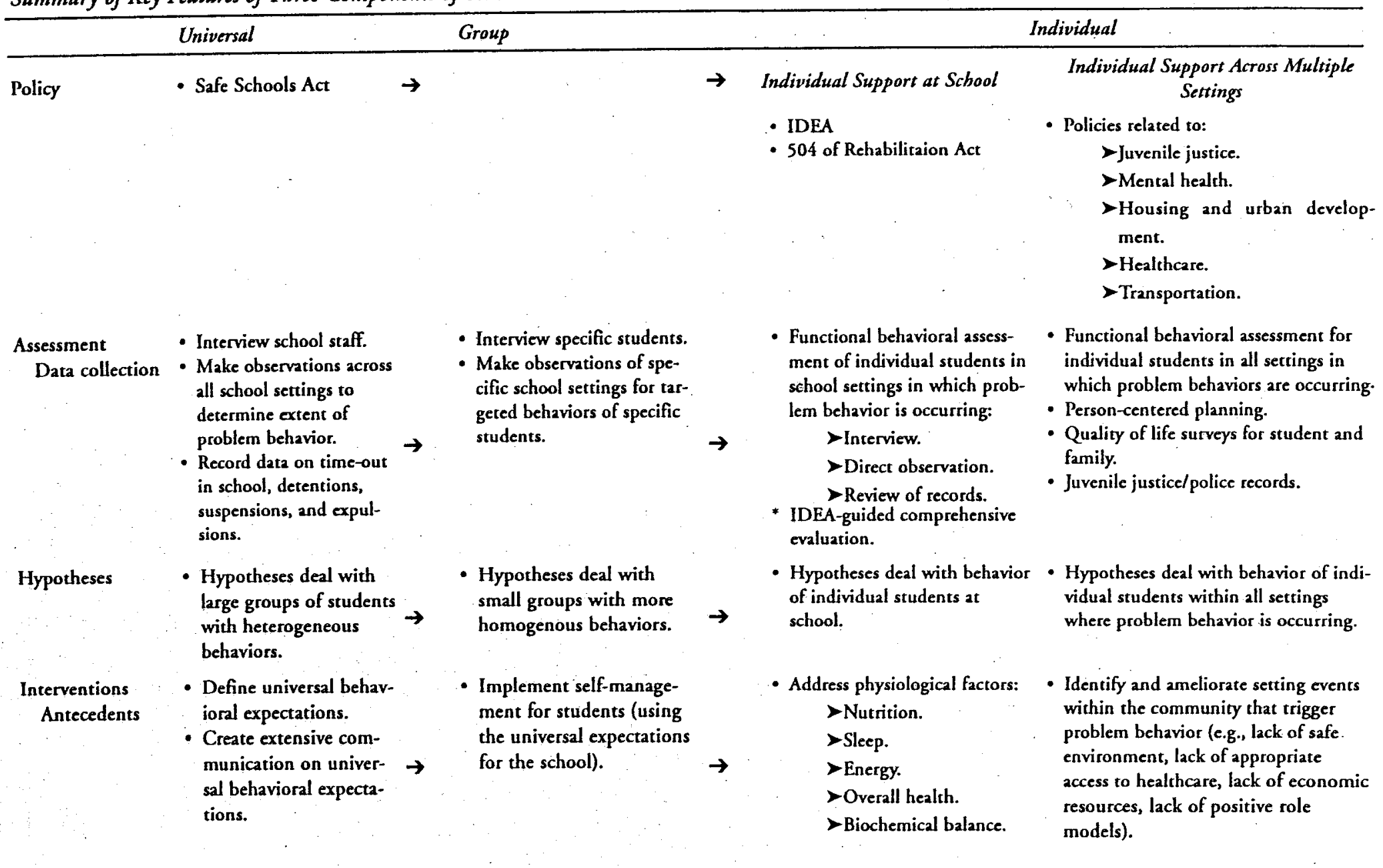


TABLE 1

(Continued)

Universal

Group

Individual

Individual Support at School

- Alter the physical environment: - Noise, light, and other sensory stimuli.

-Class placement

- Room arrangement and seating.

- Increase choice making: Encourage preferences and decision making.

-Incorporate preferences throughout all activities.
- Make curricular adaptations: -Preteaching.

- Tasks-interspersal.

-Appropriate length

> Self-management.

- Increase predictability and scheduling:

-Use visual or written

schedule.

- Prepare students in advance

for changes and transitions.

- Develop state-of-art services and supports.
Individual Support Across Multiple Setting

- Develop collaborative partnerships with stakeholders

(e.g., wraparound, juvenile justice, mental health).

- Implement neighbor-

hood/block parent watch.

- Share data about improvements with stakeholders to leverage resources (e.g., business establishments, educational institutions, community leaders, neighborhood associations). 
TABLe 1

(Continued)

\begin{tabular}{|c|c|c|c|c|c|}
\hline & Universal & & Group & Indiv & idual \\
\hline \multirow{3}{*}{ Skills } & & & & Individual Support at School & $\begin{array}{l}\text { Individual Support Across } \\
\text { Multiple Settings }\end{array}$ \\
\hline & $\begin{array}{l}\text { Teach universal expecta- } \\
\text { tions to all students in all } \\
\text { settings. }\end{array}$ & $\rightarrow$ & $\begin{array}{l}\text { - Provide setting-spe- } \\
\text { cific instruction of } \\
\text { expectations for tar- } \rightarrow \\
\text { geted students. } \\
\text { - Teach social skills. }\end{array}$ & $\begin{array}{l}\text { Teach skills: } \\
\text {-Academic skills to } \\
\text { succeed in classes. } \\
\text {-Advocacy skills to } \\
\text { make systems change. }\end{array}$ & \\
\hline & $\begin{array}{l}\text { - Teach replacement skills: } \\
\text {-A different way to } \\
\text { accomplish purpose } \\
\text { without problem } \\
\text { behavior. } \\
\text { - Problem-solving skills } \\
\text { in generating appro- } \\
\text { priate alternatives to } \\
\text { problem behavior. }\end{array}$ & & 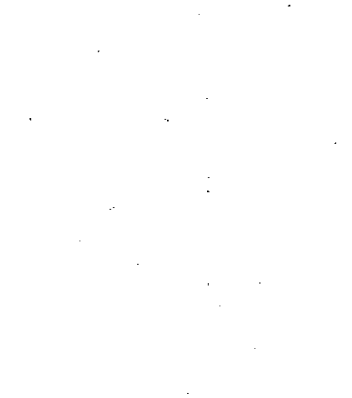 & $\begin{array}{l}\text { Social skills to interact } \\
\text { successfully in multiple } \\
\text { environments. } \\
\text { - Community service } \\
\text { skills to make produc- } \\
\text { tive contributions. } \\
\text { Communication skills } \\
\text { to problem-solve, nego- } \\
\text { tiate, and mediate prob- } \\
\text { lems. }\end{array}$ & . \\
\hline Consequences & $\begin{array}{l}\text { Provide a universal positive } \\
\text { reinforcement system. }\end{array}$ & $\rightarrow$ & $\begin{array}{l}\text { Provide a reinforce- } \\
\text { ment system for } \\
\text { groups of students. } \rightarrow\end{array}$ & $\begin{array}{l}\text { Provide a reinforcement } \\
\text { system for individual stu- } \\
\text { dents in school settings. }\end{array}$ & $\begin{array}{l}\text { Provide a reinforcement } \\
\text { system for individual stu- } \\
\text { dents across multiple set- } \\
\text { tings. }\end{array}$ \\
\hline
\end{tabular}


The key features of universal support include (Sugai et al., 2000)

- Clearly defining three to five universal behavioral expectations in simple, succinct, and positive ways.

- Explicitly teaching expectations so that all students know exactly what is expected of them.

- Extensively communicating the universal expectations on a schoolwide basis (i.e., rewarding and acknowledging by "catching students being good").

- Comprehensively implementing a schoolwide positive reinforcement system.

- Evaluating progress through a team process and making adaptations based on data.

All school staff then work together in implementing universal support across all school settings for all students. Data (as previously described) are systematically collected to monitor progress toward the reduction of problem behavior as indicated by the reduction in punitive discipline.

\section{CASE STUDY}

At the beginning of the first year (1998-1999) of developing and implementing schoolwide PBS at Central, teachers, students, and administrators were interviewed about their concerns involving problem behavior. This interview process revealed significant concerns related to (a) having a large number of new students at Central, and (b) spending an exorbitant amount of time inefficiently and ineffectively "teaching" the students various versions of school rules or expectations throughout the entire year.

After further questioning and working with school staff, the term "becoming Centralized" emerged as a useful construct to explain a mutually agreed on set of behavioral expectations or "school rules" at Central. Students, teachers, and administrators were asked to operationally define what it meant to be "Centralized." Five schoolwide expectations emerged: be safe, be cooperative, be ready to learn, be respectful, and be responsible. The next goal was to directly teach these schoolwide expectations to all students in multiple settings. Central staff refer to this process as teaching all students the "Five Steps to Success."
A schoolwide positive referral/ticket

system was also developed to reinforce

desirable behavior.

A small, informal group of administrators, teachers, and University of Kansas researchers emerged as a schoolwide PBS team to work with the Central staff on enabling all students to learn the "Steps to Success." This working group nominated one teacher--Central's physical education teacher --to meet with each of Central's four "houses" (i.e., smaller organizational units or "schools within the larger school") to identify generic instructional needs and settings (e.g., cafeteria and hallways) in which instruction was needed.

Teachers and students developed codes of conduct around the five universal expectations. The codes described the specific behaviors expected by all students and staff within each classroom and in other school settings. Teachers used lesson plans, developed by the informal Central PBS team and University of Kansas staff, to directly teach these universal expectations in their classrooms. The major components of these lesson plans for teaching each of the five schoolwide expectations included (Taylor-Greene et al., 1997):

- Introduction of the specific skill to be taught (e.g., "being cooperative").

- Provision of a rationale for acquiring the skill that was generated by the students themselves (e.g., student friendly and student-validated).

- Description of the specific setting(s) in which instruction would be provided.

- Listing of nonexemplars (negative examples) and exemplars (positive examples) of the expected behavior.

- Opportunities for students to practice nonexemplars (which was a highly preferred activity for the students; that is, to get to "pretend" to practice inappropriate behaviors briefly first, before practicing "correct" behaviors) in order to generate "behavioral momentum." 
- Opportunities to practice and receive feedback on the performance of expected behavior (exemplars).

- Awarding of certificates of achievement; (e.g., "Certified Hallway Walkers").

- Public recognition for students who met criteria demonstrating a specific universal expectation; for example, students who were successful in demonstrating "being safe" behaviors in the hallways were acknowledged as "Certified Hallway Walkers" via a school announcement over the public address system.

A schoolwide positive referral/ticket system was also developed to reinforce desirable behavior. On each of these tickets was listed: (a) the five expectations for the school, (b) a blank for the student's name, and (c) a blank for the teacher's name. Teachers and other school staff were encouraged to "catch" students engaging in one or more behaviors related to the five expectations and to issue a positive referral ticket for the student's desirable behavior. Teachers were also asked to check off which one of the five universal expectations the student had demonstrated. Each student who was awarded a positive ticket would then place the ticket in a box in the main school office. By the end of the school year, separate boxes were arranged for each of the three grades so that each day there was a lucky winner from each grade. At the beginning of each day the vice-principal pulled tickets from each of the three boxes. Over the school's intercom system she called out the student's name, stated which universal expectation the student had followed appropriately, and asked the student to come to the office. Teachers reported that a "Price is Right" effect occurred; that is, students cheered for one another as they were called to "come on down" to the office.

Once the three students, one from each grade, reached the office, the vice-principal took their pictures, escorted them to a display case where they selected a prize, and then mounted their pictures with a statement of what expectation(s) they had followed. Students in the building passed this display case daily on their way to lunch.

Teachers reported this procedure has resulted in

- More positive interactions between them and their students.

- A sense of accomplishment in noting the reductions in office discipline referrals when reviewing the schoolwide data.

- A perception on the part of students in special education that they are "a normal part of the school" when they are acknowledged for engaging in a universal expectation (Edmonson, 2000).

Having described how universal support was implemented schoolwide at Central, we will turn our attention to Jeremy and examine how universal support imp acted him.

Teaching universal expectations addressed Jeremy's need for a more structured environment where expectations for his behavior were (a) the same as for other students, (b) clearly communicated in writing, and (c) verbally taught and reinforced by teachers and staff in all settings and environments. Jeremy's three major problem behaviors (inappropriate touching or grabbing; loud and disruptive talk-outs; and off-task behaviors) reflect nonexemplars of three of the five Central expectations, respectively, as follows: (a) being safe, (b) being respectful, and (c) being ready to learn. Instruction at the level of universal support most certainly increased Jeremy's access to adult attention in multiple settings for engaging in behaviors that were exemplars of one or more of Central's five universal expectations.

Perhaps the clearest evidence that Jeremy derived substantial benefit from universal support was that he began to read aloud from the omniposted "Five Steps to Success" signs, making statements such as "I am being cooperative," or "I have my pencil. I am ready to learn." Functionally, Jeremy appeared to incorporate the five universal expectations as rules to guide his own behavior and then self-monitor his own exemplars or nonexemplars of these five behaviors--all without any additional support required from teachers beyond acknowledging and praising him occasionally.

There were also instances when the universal teaching of expectations did not decrease problem behavior for Jeremy and other students. For example, Jeremy continued to experience significant behavior problems, such as grabbing others 
or inappropriately touching them (i.e., not being safe), while walking down the hallway and making the transition to and from classes and other activities. In addition, Jeremy's loud and disruptive episodes of talking out (i.e., not being respectful) were not significantly improved as a result of universal support alone. These two categories of problem behavior required more intensive support for Jeremy. However, some progress was certainly made in Jeremy's ability to keep on task (i.e., being ready to learn) as a result of his participation in universal support.

\section{GROUP SUPPORT}

\section{OVERVIEW}

The second component of PBS, group support, recognizes that some students' problem behavior is not sufficiently addressed through universal support. If a school has a relatively large group (e.g., 10-15 or more students) who have received universal support but continue to experience patterns of problem behavior, then the school needs an additional, efficient PBS system component for responding to the needs of these students (Hawken \& Horner, 2001).

Often students who need more intense intervention than universal support still do not need individual support. Group support is a means by which administrators and teachers can provide PBS in the largest unit that is feasible for the particular students in need of more intensity. Examples of group support include "checkin/checkout" systems used for groups of students with chronic problem behavior, as well as classroomwide self-monitoring and self-management systems. These group systems typically rely on student team-level self-assessment (self-monitoring in peer dyads, for example) of behavioral expectations, accompanied by periodic (and often unpredictable) "reliability" checks by teachers. This assessment is followed by access to group reinforcers on various changing schedules, contingent on meeting or exceeding criteria for reinforcement.

The same policy that influences universal support also applies to group support--the Safe and Drug-Free Schools and Communities Act (1994). As highlighted in Table 1, data collection moves from the general tallying of data for many students to a behavioral assessment for smaller groups of students. The goal of the assessment is to determine the patterns of appropriate and inappropriate behaviors among groups of students. The data collection at the group level involves interviews and direct observations across different school settings. The goal is to establish hypotheses for addressing problem behavior for groups of students, ranging in size from small to large. In terms of assessment for group support at the classroom level, teachers might ask questions such as:

- When does my class seem to have the most and least problems?

- Why do I send more students to the office right after lunch than any other time of the day?

- Why do certain groups of my students seem to always cause problems in the cafeteria?

Once these group patterns of problem behavior are established, the next step is to implement support at the group level so that multiple students benefit simultaneously. Group support is a "step-up" in intensity from universal support and often represents "reteaching" specific instances of universal expectations in smaller groups so that students are provided more systematic and intensive instruction. Group support may also require teaching groups of students many different examples of a specific universal expectation.

\section{CASE STUDY}

Teachers at Central have provided group support in a number of successful ways. It became apparent that even after providing universal support in going to and from the cafeteria at lunchtime, walking safely and being cooperative was still a problem for some students. The PBS team utilized a schoolwide lesson format, generated by the school staff, to provide group-level instruction to students in these classrooms. The skill development process involved gathering the students in small groups in their classrooms and asking them to list what "being cooperative" to and from the cafeteria did not look like ("the uncool way") and did look like ("the cool way"). Next, the students were asked to generate rationales for being cooperative during these transitions (e.g., we stay safe, we get to lunch on time, we have more time to 
eat). A behavioral momentum approach was used to increase the likelihood the students would participate in the process (Dunlap \& MorelliRobbins, 1990). Briefly, this approach involved providing initial opportunities for the students to demonstrate and receive feedback on nonexemplars of the inappropriate behaviors (in this case, "uncool way"), which was a fun, easy, entertaining, and highly preferred behavior for the students to do. When sufficient "momentum" had been built up by practicing these nonexemplary behaviors and receiving feedback, the task then shifted to asking the students to demonstrate exemplars of appropriate, acceptable ways of behaving (in this case, the "cool way" of walking to and from the cafeteria). It should be noted that the Central students were cautioned prior to the "uncool" demonstration not to engage in "serious offenses" that could result in their removal from the school. As expected, all targeted groups immediately (and eagerly) were able to demonstrate "uncool" transition behavior. Next, the students were asked to demonstrate "cool" (cooperative) transition behavior (for example, walking not running, avoiding bumping into others, walking with hands at your side, being quiet while walking, and walking in a line and at an acceptable distance behind the person in front of you). The school staff reported that group support was helpful in enabling them to redirect students in the hallway by asking them if they were being "cool' or "uncool" as contrasted to having more directive or punishing interactions with them (Edmonson, 2000).

Jeremy was included in the group support component that addressed being cool hallway walkers. He learned that walking in the hallway meant not talking out loud and that his class mates would not respond to (and reinforce) this behavior, since talking out loud was not an acceptable behavior of walking down the hallway. $\mathrm{He}$ also learned that appropriate hallway walking meant keeping your hands either at your side or in your pockets and not reaching out to touch or grab people who passed by you. Thus, group support had a positive impact on reducing these two problem behaviors in two specific school settings: hallways and the cafeteria. Additionally, after instruction, Jeremy continued to use the terms "cool" and "uncool" to self-manage and self-evaluate his performance on transitional hallway-walking behaviors (e.g., "I am being uncool", and "I am being cool.").

While group support was helpful for improving and controlling the antecedents affecting Jeremy's talking-out and inappropriate touching/grabbing behaviors in the hallway and cafeteria, it was not sufficient to reduce the behavior to acceptably low levels across all settings. Additional support was needed to identify the additional triggers for these two problem behaviors and to plan successful supports to replace his problem behavior with appropriate behavior.

\section{INDIVIDUAL SUPPORT}

\section{OVERVIEW}

Individual support is the core intervention that is typically provided to students with disabilities who have problem behaviors, although many students who do not qualify for special education services benefit from individual support. Individual support can be provided solely in school settings, or it can also be provided across multiple settings.

Individual Support at School. It is at this point that the policy guidance is expanded from being grounded in the Safe and Drug-Free Schools and Communities Act to IDEA and Sec. 504 of the Rehabilitation Act. IDEA's guidance on PBS is at several points:

- IDEA provides that, during development, review, and revision of an IEP for a child whose behavior impedes his or her learning or the learning of others, the IEP team must "consider, if appropriate, strategies including positive behavioral supports, strategies, and supports to address that behavior" (34 C.F.R. $300.346 \quad$ (a)(2)(i) [1999]).

- If the IEP team then determines that a child needs a particular service (such as PBS) after this consideration, a statement to that effect must be put in the IEP (34 C.F.R. 300.346 (c) [1999]).

- IDEA makes it clear that it is appropriate for a child's general education teacher, as well as his/her school social worker or provider of psychological services to participate in the development and 
implementation of PBS (34 C.F.R.

$300.346 \quad(d)(1) ; \quad 300.24 \quad$ (b)(8), $\quad$ (13)

[1999]).

- A PBS plan that has been developed as part of the IEP (as previously described) is considered the behavioral support plan required by certain IDEA disciplinary procedures, which promotes proactive behavioral planning (34 C.F.R. 300.520 (b)(1)(i); 64 Fed. Reg. 12,620 [1999]).

IDEA does not use the term problem behavior. Rather, IDEA language refers to behavior that "impedes" one's own learning or the learning of others. The definition of "impedes" is not included in the statute. A policy analysis of PBS statutes and case law in the disability field led a research team to define the term impeding behavior, to mean those behaviors of a student that (Turnbull, Wilcox, Turnbull, Sailor, \& Wickham, 2001)

- Impede the learning of the student or of others including those behaviors that are externalizing (such as verbal abuse, aggressions, self-injury, or property destruction); internalizing (such as physical or social withdrawal, depression, passivity, resistance, social or physical isolation, or noncompliance); manifestations of biological or neurological conditions (such as obsessions, compulsions, stereotypes, or irresistible impulses); and disruptive (such as annoying, confrontational, defiant, or taunting behavior).

- Could cause the student to be disciplined pursuant to any state or federal law or regulation or could cause any consideration of a change of the student's educational placement.

- Are consistently recurring and therefore require functional behavioral assessment and the systematic and

Individual support is the core intervention that is typically provided to students with disabilities who have problem behaviors. frequent application of positive behavioral supports.

PBS involving individual support, some of which occurred in a school setting, has been the focus of research in the disability field over the last 15 years. A review of over 100 research articles published between 1985 and 1996 that investigated the behavioral outcomes for individuals with impeding behavior concluded (Carr et al., 1999)

- $\quad$ PBS was successful in achieving at least an $80 \%$ reduction in impeding behavior for approximately two-thirds of the behavioral outcomes that were studied.

- The success of PBS is substantially enhanced when a functional assessment is carried out as the basis for planning the support(s).

- PBS is more effective when significant people (for example, educators and families) change their behavior as contrasted to when only the individual with impeding behavior changes.

- $\quad$ PBS is more effective when the environment is reorganized as contrasted to when the environment is not reorganized.

- $\quad$ PBS is more effective when it is carried out by significant people in the individual's life (for example, educators and families) than by people who do not have ongoing relationships with the individual (for example, researchers and clinicians).

- $\quad$ PBS works just as effectively with individuals who have multiple disabilities as with individuals who have a single disability.

At the heart of individual support is a functional behavioral assessment (FBA), which identifies specific relationships between behaviors and the circumstances that trigger behaviors that impede a student's ability to learn (Lane, Umbreit, \& Beebe-Frankenberger, 1999; O'Neill et al., 1997; Reid, 2000; Sugai, Lewis-Palmer, \& Hagan-Burke, 1999-2000). Information about the student's overall patterns of behavior, the con ditions that seem to predict that the behavior will occur, and possible reasons for the behavior then become the foundation for hypotheses that guide individualized support. In the continuum of assessment moving from less intensive to more in data collect on and hypothesis-generating procedures, it is at this level-individual support-that assessments step up from a more generalized approach to an individualized and function-based set of procedures. 
To emphasize the importance of the FBA, IDEA requires such assessment as well as behavioral support planning in certain disciplinary cases (34 C.F.R. 300.520 (b) [1999]).

Not only is there more intensity of assessment at this level, but there is also more intensive interventions. Rather than interventions being planned at universal or at group levels, the unit of analysis moves to the individual student. As listed in Table 1, there are numerous ways to provide intensive interventions related to antecedents, skills, and consequences. The bulk of research within the developmental disabilities field has been focused on individual supports using the strategies identified in Table 1 .

The PBS team at Central considered Jeremy's behavior in terms of his needs, as related to the five universal expectations ("Five Steps to Success"). They concluded that Jeremy needed more intense adaptations and instructional programs for being safe, being respectful, and being ready to learn. Jeremy was able to be responsible and to be cooperative with the universal and group support provided to other students.

Jeremy's IEP team made the decision to conduct an FBA to analyze the following behaviors of concern:

- Inappropriately touching peers or adults (Be Safe).

$>$ Grabbing or inappropriately touching others when they are walking by or when they are standing or sitting close by (e.g., in a classroom work group) and within an arm's length.

$>$ Attempting to "recruit" touching behavior by telling others in a loud voice to "shake my hand."

- Inappropriate verbal disruptions (talk-outs) (Be Respectful).

$>$ Asking the teacher repetitive questions (e.g., "Have I been bad?") or repetitively calling out the teacher's name in a loud voice.

$>$ Talking out loudly during lessons or quiet work time, either by making out-ofcontext remarks (e.g., "Spiders are unsanitary") or by talking without first raising hand and being acknowledged.

- $\quad$ Off-task (Be Ready to Learn).

$>$ Drawing pictures, faces, maps, etc. in stead of working on assigned tasks.
Staring off into space or silly laughing, and not listening to instructions to get out paper, pencil, books, or other materials and work on assignments.

$>$ Getting out of his seat without permis sion to throw something away, or to look at something.

The PBS team then turned their attention to selecting appropriate measures to understand the functions of Jeremy's behavior. In talking with the team, including Jeremy's mother, no physical or medical reasons could be identified for the three classes of target behaviors, so functional as sessments focused on learning and behavioral areas. After conducting various interviews and making multiple direct observations across several classrooms and' other school settings, a number of factors were identified that the PBS team believed either strongly predicted, set up, or directly triggered Jeremy's problem behavior. These included specific setting events, environmental features, immediate antecedent triggers, and particular instructional methods that were mismatched to Jeremy's learning style preferences. Table 2 lists FBA tools that were selected by Jeremy's PBS team, along with a brief rationale for their use, to determine possible hypotheses about the function or purpose of Jeremy's challenging behaviors.

As a result of the systematic exploration of Jeremy's problem behavior through the FBA process, the team found the following:

- Problems do not occur when Jeremy is

$>$ Engaged in drawing.

$>$ Situated in a quiet room.

$>$ Working in a more isolated area of the room.

$>$ In settings where there is little or no movement/transitions by others.

$>$ In a classroom where no one enters unexpectedly.

$>$ Working on preferred tasks or routines that are kept brief (10 minutes or less) and predictable

$>$ Getting frequent, positive adult attention.

$>$ Allowed to review (and rewrite in his Social Stories notebook) schoolwide expectations (5 Steps to Success) and the school 


\section{TABLE 2}

FBA Tools, Use, and Contribution to Behavior Support

\begin{tabular}{ll}
\hline Tools & Use \\
\hline Initial FBA Questions & Screen for possible psychological, \\
& environmental, and learning factors. \\
(Structured Interview) & Collected with focus student, family \\
& members, teachers, and administrators to \\
& learn about setting events, environments, \\
& potential physical/medical/health factors.
\end{tabular}

Contribution to Behavior Support Plan

- Entree to begin talking about, the behavior.

- Uses interview to help to determine student team membership.

- Begins to operationally define the behavior and describe possible hunches for the behavior (e.g., physiological, environmental, or educational).

- Documents information about the behaviors occurrence and nonoccurrence.

Review of IEP, Student Progress Screen for psychological, environmental, Reports, School Records, Other and learning factors; past Documents successes/failures. Conducted by a school (Document Review) team member to learn about history of problem behaviors, any previous successful or unsuccessful strategies, etc.

- Provides data on how long the target behavior has been in the student's repertoire.

- Enables team to gather information about history of successfulinterventions (with this target behavior or others).

- Documents any past physiological, environmental, behavioral, or learning factors present.

\begin{abstract}
ABC Chart, Interval Observations, Scatterplot (Touchette, MacDonald, \& Langer, 1985)
\end{abstract}

(Direct Observation)

Motivation Assessment Scale (Durand \& Crimmins, 1988)

(Interview Questionnaire)
Data collection for behavioral factors. Collected by someone with some training in observational data collection across multiple problem environments once the problem behavior(s) are operationally defined to learn antecedents (A) and consequences $(\mathrm{C})$ of targeted problem behavior(s) (B).

Data collection for behavioral factors. Collected by self-report/interview or observation to form preliminary hypotheses re: the function of the target behavior(s), using a 16-item survey that addresses four functions: sensory, escape, attention, and tangible.
- Provides data about frequency of target behaviors.

- Enables team to identify behavioral patterns regarding times of the day and settings.

- Enables team to determine function of target behavior.

- Provides a large range of behaviors and functions for team, allowing team to consider multiple responses. 
TABLE 2 (Continued)

\begin{tabular}{|c|c|c|}
\hline Tools & Use & Contribution to Behavior Support \\
\hline $\begin{array}{l}\text { Checklist for Teachers/Staff of } \\
\text { Problematic Routines and Classes } \\
\text { (adapted from March, Horner et al., } \\
\text { (1999) } \\
\text { (Interview/Observation/Self-Report) }\end{array}$ & $\begin{array}{l}\text { Data collection for environmental factors. } \\
\text { Collected through observation and/or interview } \\
\text { across multiple problem classes or times of the } \\
\text { day once the behavior(s) are operationally } \\
\text { defined to learn problematic classes or school } \\
\text { routines. }\end{array}$ & $\begin{array}{l}\text { - Provides data about occurrence of target } \\
\text { behavior within school routines and } \\
\text { specific classes. } \\
\text { - Enables teams to identify behavioral } \\
\text { patterns regarding routines and } \\
\text { classroom activities. }\end{array}$ \\
\hline $\begin{array}{l}\text { Checklist for Multiple Intelligences } \\
\text { (adapted from Armstrong, 1994) } \\
\text { (Interview/Observation/Self-Report) }\end{array}$ & $\begin{array}{l}\text { Data collection for learning factors. } \\
\text { Collected by self-report/interview or } \\
\text { observation to determine what learning styles } \\
\text { are preferred andnonpreferred by the student } \\
\text { with impeding behavior. }\end{array}$ & $\begin{array}{l}\text { - Provides team with informationabout } \\
\text { how classroom activitiesand student's } \\
\text { learning should be designed to match } \\
\text { student's pre ferred learning modalities. } \\
\text { - Lists preferred and nonpreferred learning } \\
\text { styles. }\end{array}$ \\
\hline
\end{tabular}

district's code of conduct to help selfmanage his behavior.

- Problems do occur when Jeremy is

$>$ In a classroom, the cafeteria, or another setting that becomes quite loud.

$>$ In settings with excessive movement going on, and loss of structure and predictability.

$>$ Receiving attention following inappropriate behaviors.

$>$ Walking on the way to the bus.

$>$ Bored.

$>$ In the fifth hour (generally, from 10:22 12:22 p.m.), especially just before lunch.

$>$ Sitting near one or two specific peers who intentionally mimic or mock his behaviors.

Using interviews, observations, and other FBA information, the PBS team hypothesized that two of the targeted behaviors (nappropriate touching, inappropriate verbal disruptions) might be maintained by attention and that the third problem behavior (off-task) might be maintained by escape from class work. The PBS team at Central then designed ways to test their hypotheses and, thus, verify their hunches. For example, the team tested the hypothesis that adult attention was maintaining talk-outs by having the teacher provide the same tasks to Jeremy under two different conditions. In one condition, no adult attention was given when he talked out; and in the other condition, his talk-outs triggered adult attention. By recording and observing his behavior, it became obvious to the team that Jeremy's talk-out behaviors increased dramatically when he received adult attention for talking out. When Jeremy did not get adult attention for talking out, talk-outs occurred much less frequently. The PBS team's conclusion was that adult attention was maintaining Jeremy's talk-outs.

When adult attention was held constant(i.e., Jeremy received moderate rates of positive attention on a varied interval schedule during the observational period) but task difficulty and task type were varied, Jeremy's off-task behaviors were noticeably less frequent under conditions of moderately-to-highly preferred tasks (tasks that were not difficult for him) as well as task types that allowed "hands-on" engagement. The PBS team's hypothesis was confirmed that Jeremy's off-task 
behaviors functioned as a means of escape or avoidance whenever he perceived tasks to be less preferred, more difficult, or as requiring nonspatial, nonconcrete, and abstract-verbal listening and problem-solving skills.

The team then met to brainstorm various ways to change setting events and immediate antecedents that tended to set up or trigger problem behavior, as well as to identify how to provide Jeremy with attention for appropriate rather than inappropriate behavior, and to find ways of reducing his need to escape specific task demands. This information was compiled, along with a summary of the FBA information, into a highly intensive PBS plan. Jeremy's PBS plan is linked and cross-referenced to his IEP by a series of goals and objectives that relate specifically to his problem behavior and that are based on the summary of FBA information and hypotheses about the functions of his problem behavior. Table 3 summarize; the key points of Jeremy's PBS plan that primarily focuses on inappropriate verbal disruptions (talk-outs).

The process of conducting the FBA, as well as developing and then implementing the positive behavioral support plan has been beneficial fox the staff at Central. Jeremy still has some problem behavior that does not fully meet the school's five universal expectations. However, the staff are learning to control their own reactions to his behavior so that they provide the most conducive environment for Jeremy to enhance his own selfmanagement. Also, because they engaged in a team process, there is a group of knowledgeable and committed people available who can offer support, not only to Jeremy, but to his family and each other, as well. Interestingly, teachers reported that working intensively on behalf of an individual student in actuality improves the learning environment for many other students (Edmonson, 2000). Thus, although the intervention for Jeremy was targeted on him individually, what teachers learned in the process had broader benefits.

In the process of providing FBA interview information to the PBS team, Jeremy's mother, Mrs. Jones, described feeling overwhelmed by the responsibility of providing behavioral support to Jeremy at home, especially since he has become a teenager. She expressed particular worries about
Jeremy wandering off when he is outside alone and his being socially isolated. She described his very limited involvement in any activities outside of school, his extremely narrow social network of friends, his limited interactions with his siblings, and his fears about his future after high school. She also described the profound impact of her son's problem behaviors, not just on his own lifestyle satisfaction and individual quality of life; but also on the quality of life experienced by other family members. These concerns necessitated not only providing individual support at school but also doing so across multiple settings.

Individual Support Across Multiple Settings. Some students require individual support across multiple settings. Relevant policy for individual support across multiple settings expands from the Safe School Act, IDEA and Sec. 504 of the Rehabilitation Act to broader policies covering areas such as poverty, juvenile justice, welfare reform, social security, Medicaid, 'and housing and urban development. One implication is a need for the PBS team to have comprehensive knowledge across many different policy arenas.

Assessment procedures for individual support across multiple settings require more comprehensiveness than within previous components. Building on the FBA done at school at the individual support level, more comprehensive assessment includes (a) an FBA conducted in multiple settings where the student and family are experiencing challenges, (b) a person-centered assessment process (Kincaid, 1996), (c) a quality of life survey focusing on the individual with special needs (Gardner \& Nudler, 1999; Schalock, 2000), and (d) a survey of family quality of life considerations (Park, Turnbull, \& Turnbull, 2002; Turnbull et al., 2000). Person-centered planning and quality of life inquiries are broadly focused on explicating the factors that are especially important to students and families in experiencing a sense of well-being and identifying what it would take for the student and family to be successful in multiple settings.

There are two major supports that can be extremely helpful in providing individual support across multiple settings. These two supports are community schools (Lawson \& Sailor, 2000) and wraparound services approaches (Eber, Nelson, 
TABLE 3

Highlights of Jeremy's Positive Behavior Support Plan for Inappropriate Verbal Disruptions (Talk-Outs)

\begin{tabular}{lll}
\hline Steps & \multicolumn{1}{c}{ Highlights } \\
\hline $\begin{array}{l}\text { 1. Description of target } \\
\text { problem behavior }\end{array}$ & $\bullet$ & $\begin{array}{l}\text { Asks the teacher questions without first raising hand and being } \\
\text { acknowledged during lesions. }\end{array}$ \\
& $\bullet$ & Asks the teacher repetitive questions (e.g., "Have I been bad?"). \\
& - & Uses loud voice and/or repeats person's name in a loud voice (e.g.,"You \\
& mean, Ms. B.") \\
& Makes out-of-context comments while other students are working quietly \\
& (e:g., "I don't like spiders.... spiders are unsanitary").
\end{tabular}

2. Functional behavior assessment findings

3. Hypothesis statement developed

4. Desired replacement behavior
- Has difficulty when other peers whisper near him in class.

- Tends to begin to talk louder when he hears other students whis per.

- Appears to calm down when adults whisper and even tries to model or imitate the "whisper voice."

- Imitates peers' appropriate verbal behaviors or in response to peers' imitation of his loud and excited talk.

- Talks out when teachers demonstrate anxious behaviors (e.g., shaking, cringing) or provide high levels of corrective feedback to students.

- Uses excessive and repetitive talk-out behaviors to get what he wants and to escape frustrating or less preferred tasks, especially when he is told to wait for something he wants or is told that he cannot interact with a particular preferred person or object.

- Uses talk-outs to get or obtain adult and/or peer attention.

- Uses talk-outs to reduce/alleviate stress, anxiety, and/or tension, or to express his emotions, especially when his energy level is high, and he needs to interact with peers and adults.

- To work quietly in class and refrain from making out-of-context comments that disrupt the lesson.

- To raise hand and wait to be acknowledged before calling out answers to questions and before talking out in class.

- To ignore peers' comments that taunt or mimic him.

- To engage in quiet self-talk to remind himself of the class rules about not talking out in class.

- To read and recopy social stories as a way of reinforcing positive behaviors in writing. 
TABLE 3

(Continued)

Steps Highlights

5. IEP goals and

objectives developed

Goal \#3: Jeremy will improve his skills in language and communication Objective: Jeremy will work quietly in class and refrain from making outof-context comments that disrupt the class.

Objective: Jeremy will raise his hand and wait to be acknowledged before calling out answers to questions or talking out about things in class.

Objective: Jeremy will ignore and/or redirect himself by practicing quiet self-talk or reading social stories to himself, in response to comments made by peers that taunt or mimic him.

Program guidelines were established using the FBA data to include:

- $\quad$ Prompting With no more than one verbal or gestural/pointing prompt (redirection) per class.

- Criteria: Jeremy demonstrates 9 of 10 "positive behavior" opportunities; also, a decrease in target (problem) behaviors of $80 \%$ below baseline measures of in appropriate verbal disruptions (talkouts) 4 of 5 days.

- Review and Evaluation: As measured by data collected.

6. Create interventions based on FBA

\section{Strategies to Change Setting Events}

- Schedule functional activities and build routines that offer opportunities for Jeremy to move around and burn energy, especially prior to times/activities that are predictable triggers for disruptive talkouts, such as 5th hour from10:20-12:20.

Strategies to Change Immediate Antecedent Events

- $\quad$ Offer more assistance -- with minimal verbal interaction -- when presenting new or difficult tasks, or when working on assigned tasks at nonpreferred times of the day; e.g., 5th hour or late in the day when disruptive talk-outs are much more likely.

Strategies to Teach New, Desired Replacement Behaviors

- Teach Jeremy to self-monitor and self-manage talk-outs by using his social stories.

- Teach him how to appropriately terminate a nonpreferred task without talking out disruptively by showing him how to use an acceptable form of behavior that accomplishes the function, for example, "Stop." (This communication form could be to raise or wiggle his hand, wait to be acknowledged, then say. "Stop, please," or "Need to `cool down' now.")

- Use gestural/physical, proximity prompts, but minimum verbal directions, to get him going on one or more of the crisis management procedures.

Consequence Strategies to Strengthen Existing, Alternative Desired

Behaviors

- Continue to teach Jeremy to wait longer periods of time without getting undivided adult attention by reducing proximity cues, giving nonverbal gestures (without eye contact) to wait, introducing social reinforcers frequently, etc.

- Rehearse and role play with Jeremy what to do when peers tease or mimic him, trying to get him to say silly things that just get him into trouble. 
TABLE 3

(Continued)

\begin{tabular}{|c|c|}
\hline Steps & Highlights \\
\hline $\begin{array}{l}\text { 8. Monitoring procedures } \\
\text { for IEP team }\end{array}$ & $\begin{array}{l}\text { - Intervene physically between Jeremy and others to prevent injury or damage to } \\
\text { property. } \\
\text { - Remove Jeremy from the situation/setting that is triggering the problem } \\
\text { behavior in order to effectively manage and de-escalate the crisis. Escorthim } \\
\text { down the hallway and prompt him to work appropriately in order to de-escalate } \\
\text { his agitation. (He can be taken into the counseling office and seated in one of } \\
\text { the chairs, in order to review social stories and work on self-management skills) } \\
\text { - Honor immediately either an independently initiated request by Jeremy to } \\
\text { appropriately "escape" or a prompted request for a break or to } \\
\text { terminate/suspend the activity. } \\
\text { - Use a frequency count of problem behavior occurrenceson a daily basis using } \\
\text { Jeremy's self-monitoring data and teacher-maintained data. } \\
\text { Assess percentage of times and situations where problem behavior is not used } \\
\text { and alternative skills are practiced. } \\
\text { Review data atmonthly meeting with team (including family). }\end{array}$ \\
\hline
\end{tabular}

Miles, 1997). In community schools, supports are provided to link students and staff to the vast array of services provided by the school and other community agencies (Calfee, Wittwer, \& Meredith, 1998; Dryfoos, 1996; Sailor, 2002). The key characteristic of community schools is having a single point of entry in terms of the comprehensive delivery of services for children (e.g., health care, recreation, child care, mental health counseling, juvenile justice, job services) and adult family members (e.g., adult education, transportation, job training, health services, protective services, financial aid). Interestingly, most of the research and model development on community schools has occurred within the general education rather than special education field, and literature on community schools does not typically appear in the special education literature. A recent investigation of the United States General Accounting Office (2000) reported that most initiatives related to community schools initiatives have not been rigorously evaluated in terms of outcomes; rather they have reported better attendance and higher graduation rates for students who have been involved. One approach, the career academy, has resulted in students at risk for school failure having significant increases in credits earned for graduation and a significant cut in dropout rates based on a 10-year study. A major area for future development is to embed schoolwide PBS into community schools so that there is a responsive context for carrying out the component of individual support, especially when individual support is needed across multiple settings.

The second comprehensive model that is available in the disability field is the wraparound services model. Primarily operational within the mental health field, wraparound is a process-driven by the needs of children and families -for providing services to meet priority needs (Burns \& Goldman, 1999; Clark, Lee, Prange, \& McDonald, 1996; Eber, et al., 1997; VanDenBurg \& Grealish, 1996). Wraparound teams are comprised of families, professionals representing a variety of agencies, the focus student, and other interested stakeholders who think creatively about how to merge resources and services so that the "whole is greater than the sum of the parts." Essentially, wraparound is an approach for building comprehensive support on a student-by-student basis when community schools are not available. Research has documented a decrease in problem behaviors and more favorable outcomes for stu- 
dents with problem behavior through wraparound services as contrasted to more traditional services (Bruns, Burchard, \& Yoe, 1995; Evans, Armstrong, \& Kuppinger, 1996).

The availability of community schools minimizes the need to work on a student-by-student basis to merge comprehensive resources. Thus, community schools operate at the systems level whereas wraparound is an approach for pulling together resources at the student and family level.

Approaches for individual support across multiple settings vary according to the intensity of students' needs. In Jeremy's situation, there are some areas of need that require individual support across multiple settings, but they are not highly complex needs. A full wraparound approach is not necessary in his situation, but rather a coordinated effort is in order between school, home, and other important community environments.

In conducting FBA interviews with Mrs. Jones and doing FBA observations in-Jeremy's home, it became clear that Mrs. Jones felt as alone in addressing Jeremy's behaviors at home and in the community as the educators did initially at school. As a result, the PBS team is in the process of introducing the following additional supports during Jeremy's eighth-grade school year to Mrs. Jones and the other members of Jeremy's family:

- Stronger use of person-centered planning processes, such as incorporating the "Choosing Outcomes and Accommodations for Children" $(\mathrm{COACH})$ planning tool (Giangreco, Cloninger, \& Iverson, 1998) into the IEP process in order to focus PBS efforts more directly on parent-identified priorities and action steps, especially in planning for Jeremy's transition to high school next year.

- More frequent and regularly scheduled (every 2 weeks) PBS team meetings with school staff, Jeremy's parents, University of Kansas research project staff, and community agency representatives to improve home-school communications and enhance partnerships among all stakeholders.

- Sharing data on Jeremy's problem behavior between school and home, using a daily behavior progress report form developed specifically to enable Jeremy to learn to selfmonitor and self-manage his three target (problem) behaviors.
- Direct instruction, modeling,: and feedback in successful PBS strategies being used at school for implementation at home, using videotaped segments of Jeremy's problem behavior from school as teaching illustrations. An offer to provide the same direct instruction, modeling, and feedback in PBS strategies to Jeremy's church community, where Jeremy. participates in the choir and Mrs. Jones gets emotional and spiritual support, or to accompany the family on any other community activity to demonstrate the use of effective PBS approaches with Jeremy in the community.

- Providing additional information on PBS and social stories (Gray \& Garand, 1993) to Mrs. Jones, and a copy of Jeremy's notebook of social stories that was written in his own words with the assistance of his speech/language therapist at school.

- Referrals, information, and linkages to support groups for parents of children with autism.

- Listening to Jeremy's family members and gathering information from interviews about the family's changing perceptions of their quality of life, as well as their perceptions of the homeschool partnership as it evolves during the current school year.

\section{EFFECTIVENESS OF SCHOOL- WIDE PBS AT CENTRAL}

Based on the referral data for the first 2 years at Central, Warren et al. (in press-a); \& Warren et al. (in press-b) found that the total number of office discipline referrals decreased by $19 \%$, inschool conferences with students (i.e., viceprincipals and counselors sitting and. discussing behavior problems with students) decreased by $23 \%$, timeouts when students are required to sit in the office for a period of time decreased by $30 \%$, in-school suspensions decreased by $12 \%$, short-term suspensions (i.e., student out of school for 1-5 days) decreased by $60 \%$, and out-of-school placements remained the same. Paired-samples t-tests were also conducted for each of the variables comparing each month during Year 1 (baseline) to the same month in Year 2 (incorporating PBS schoolwide supports). Statistically significant results were observed 
between Year 1 and Year 2 for office referrals [ $t$ (9) $=3.062, p=.014]$, timeouts $[t(9)=2.795, p=$ $.021]$, and short-term suspensions $[t(9)=5.157, p$ $=.001]$.

Although this rate of improvement is not as great as the improvement rate that has been reported from nonurban schools (Sugai \& Homer, 2001), the school and district administrators and teachers confirm this rate of progress as being substantial given the challenges that they face and, their history of addressing these challenges. Mrs. Jones, Jeremy's mother, is quick to point out that she believes that she would have ended up homeschooling Jeremy had it not been for the PBS support. It is also noteworthy that the PBS resources that were added to the school to carry out this work represented a $50 \%$ time graduate research assistant.

Given the data in Figure 2 indicating that approximately two-thirds of the students at Central experienced serious problem behavior when we started, as contrasted to approximately onefourth of students in "typical" schools, it stands to reason that the progress in significantly reducing all of the variables cited will be at a slower rate than what has been reported from "typical" schools. One of the fundamental premises of schoolwide PBS is that if universal PBS is implemented, there will only be a relatively small number of students who will need individual support and a slightly larger number that will need group support. Our experience in dealing with the urban complexities confronted by many of the students and families at Central (not by Jeremy's family) indicated that at least 200 students still .needed group and individual support. Thus, this large residual of students requiring more intensive support has caused us to rethink universal support and to consider how we can intensify support for all students in the school to more adequately address the intensity and complexity of problem behavior that we believe occurs at many urban schools.

\section{IMPLICATIONS FOR PRACTICE}

There are a number of steps that readers can take who are interested in developing schoolwide PBS models. Some of these steps include (a) expanding knowledge through current resources, (b) making time and resource commitments for professional development, and (c) intensifying universal support to address the challenges of urban schools.

\section{EXPANDING KNOWLEDGE OF CURRENT RES O UR CES}

Many resources are available to expand knowledge related to schoolwide PBS including Web sites, online modules, videos, and journals.

Web Sites. There are an increasing number of large PBS projects with comprehensive Web sites that provide extremely relevant information related to schoolwide PBS.

1. OSEP Center on Positive Behavioral Interventions and Supports, www.pbis.org. This Center, established by OSEP in the U.S. Department of Education, provides broad technical assistance, demonstrations, and dissemination to enable schools, school districts, and states to enhance their capacity for schoolwide PBS. This Web site has very helpful information on all three components of schoolwide PBS. The collaborators involved in this Center have done a significant amount of the research on schoolwide PBS. A comprehensive listing of their work is available, and some products can be downloaded.

2. Rehabilitation Research and Training Center on Positive Behavioral Support, www.rrtcpbs.org. The Rehabilitation Research and Training Center on Positive Behavioral Support, funded by the National Institute for Disability and Rehabilitation Research in the U.S. Department of Education, provides research and training related to PBS, particularly focusing on individuals with disabilities who have intensive problem behavior (individual support). A particularly helpful feature of the Web site is a comprehensive Product Directory with the most recent publications of the Center's collaborators.

3. Center for Effective Collaboration and Practice, www.cecp.air.org. The Center for Effective Collaboration and Practice has comprehensive information related to all aspects of mental health. Its mission is to support the adjustment of children with or at risk of developing serious emotional disorders. Two areas of in formation particularly relevant to PBS include FBAs and wraparound planning (individual support). 
Online Modules. The Office of Special Education Programs funded an online project in 1998 at The University of Kansas to develop Web based instructional modules for preservice teacher training. This project, referred to as the online Academy, developed modules in PBS. The developer of the PBS modules, Wayne Sailor and Rachel Freeman, developed seven modules that primarily focus on individual support. The modules are designed into the subsections of orientation, support, lessons, and practice. Students may choose multiple options for navigating through the modules. Currently, over 100 universities have down-loaded the Online Academy modules onto local servers for preservice training. Readers can get more information about the modules on www.elearndesign.org and through an article, written by the PBS module developers (Sailor et al., 1999-2000).

A second option for online modules has been developed by faculty and staff at the University of Kentucky in the form of a CD-Rom (Liaupsin, Scott, \& Nelson, 2000; Sailor et al. 1999-2000). The module includes an overview of the process of conducting FBAs, a tutorial through the steps involved, and case studies enabling students to carry out the FBA steps. Readers can get more information about the CD-Rom on the University of Kentucky's Behavior Home page: www.state.ky.us/agencies/ behave/home page.html.

Video. The OSEP Center on Positive Be havioral Interventions and Supports has developed a 23-minute video that provides an introduction to core features of schoolwide PBS. The video costs $\$ 15.00$ and can be ordered from

A particularly good way for initiating professional development on schoolwide $P B S$ is to learn firsthand from an administrator or teacher about success in another school. the following address: clavin@oregon. uoregon.edu. It is especially designed for teachers, administrators, school personnel, and parents.

Journals. Especially over the last 3 to 5 years, most, if not all, leading journals in the field of special education have published articles on PBS. Furthermore, a new journal, Journal of Positive Behavior Interventions, was developed in 1999 to particularly focus on PBS principles in home, school, and community settings. In addition to research articles, the journal also provides descriptions of successful programs, discussions of current issues, and the perspectives from a range of stakeholders, including families. Readers interested in more information can find it at: www.proedinc.com/journals.htrnl.

Journal articles that we particularly recommend to practitioners include:

- Overview of PBS--Carr et al., in press; Horner \& Carr, 1997; Weigle, 1997.

- Legal issues--Turnbull, Wilcox, Stowe, \& Turnbull, 2001; Turnbull, Wilcox, Turnbull et al., 2001; Wilcox, Turnbull, \& Turnbull, 19992000.

- Overview of schoolwide approach--Lewis \& Sugai, 1999; Todd, Horner, Sugai, \& Sprague, 1999; Sugai et al., 2000; Sugai et al., in press.

- Universal support--Horner, Sugai, LewisPalmer, \&Todd, 2001; Kartub, Taylor-Greene, March,.\& Horner, 2000; Nelson, Martella, \& Galand, 1998.

- Group support-Hawken \& Horner, 2001.

- Individual support:

$>$ Overview--Carr et al., 1999; Todd, Horner, Sugai, \& Colvin, 1999.

$>$ Functional behavioral assessment--Lane et al., 1999; O'Neill et al., 1997; entire issue of Exceptionality (Vol. 8, \#3, 19992000).

$>$ Behavior intervention plans-Horner, Sugai, Todd, \& Lewis-Palmer, 19992000; Todd, Horner, Sugai, \& Sprague, 1999.

$>$ Wraparound approach--Clark \& Hieneman, 1999; Eber et al., 1997; Handron, Doser, McCammon, \& Powell, 1998. 
Community schools -Calfee et al., 1998;Dryfoos, 1996; Lawson \& Sailor, 2000.

- $\quad$ Case studies-Chapman \& Hofweber, 2000; Lohrmann-O'Rourke et al., 2000; Nakasato, 2000; Sadler, 2000; Taylor-Greene \& Kartub, 2000.

\section{MAKING COMMITMENTS TO PROFESSIONAL DEVELOPMENT}

Based on our experience at Central, we recommend that at least a .50 position be committed to facilitating the implementation of schoolwide PBS. Further, it is helpful to have at least 1 to 2 hours of professional development on a monthly or bimonthly basis for all school personnel and to be closely connected with the process within the building focusing on prereferral and special services. This is especially important for implementing the group and individual support components.

A particularly good way for initiating professional development on schoolwide PBS is to learn firsthand from an administrator or teacher about success in another school. Information on best strategies for bridging the research-to-practice gap has pointed to the importance of practitioners gaining information from other practitioners who are in similar roles (Ruef \& Turnbull, in press). From the Web sites that we listed, a number of schools are mentioned that have successfully implemented programs. If it is not possible to get a speaker from one of these schools to provide an overview to a school faculty considering schoolwide PBS for the first time, it might be possible to connect with someone through a teleconference or to use the video that we previously described.

\section{INTENSIFYING UNIVERSAL SUPPORT IN URBAN SCHOOLS}

ts depicted in Figure 2, the challenges of urban schools can be much more complex than many other schools around the country. The U.S. Department of Education (1992) reported that the greatest number of special education students from low-income families live in urban areas as contrasted to rural and suburban areas. Furthermore, it has been reported that $70 \%$ of youth with emotional or behavioral disorders come from households with an annual income of under $\$ 25,000$ (U.S. Department of Education, 1992). In our experience at Central, we encountered many challenges of students and, families that were associated with poverty. This is consistent with research indicating that children who live in poverty are 2 times more likely to repeat a grade and $31 / 2$ more times likely to be expelled from school (Sherman, 1997). One of the lessons we learned from this experience is the heed to provide more services to all students through universal support that will hopefully serve as a deterrent to developing more intensive problems that would require group and individual support for larger numbers of students. These services include addressing needs associated with physical and mental health, transportation, nutrition, recreation, child care, and safe housing. This requires linkages with other community agencies and the coordination of integrated services across school, community, and home environments.

\section{REFERENCES}

Armstrong, T. (1994). Multiple intelligences in the classroom. Alexandria, VA: Association for Supervision and Curriculum Development. (ERIC Document Reproduction Service No. ED 374 104)

Bruns, E. J., Burchard, J. D., \& Yoe, J. T. (1995). Evaluating the Vermont system of care: Outcomes associated with community-based wraparound services. Journal of Child and Family Studies, 4, 321-339.

Burns, B. J., \& Goldman, S. K. (Eds.). (1999). Systems of care: Promising practices in children's mental health. Washington, DC: Center for Effective Collaboration and Practice, American Institutes for Research. (ERIC Document Reproduction Service No. ED 429 422)

Calfee, C., Wittwer, F., \& Meredith, M. (1998). Why build a full-service school? In C. Calfee, F. Wittwer, \& M. Meredith (Eds.), Building a fullservice school (pp. 624). San Francisco: JosseyBass.*

Carr, E. G., Dunlap, G., Homer, H. R., Koegel, R. L., Turnbull, A. P, Sailor, W., Anderson, J., Albin, R.W., Koegel, L. K., \& Fox, L. (in press). Positive behavior support: Evolution of an applied science. Journal of Positive Behavioral Interventions.

Carr, E. G., Horner, R. H., Turnbull, A. P., Marquis, J., Ivlagito-McLaughlin, D., McAree, M., Smith, C. E., Anderson-Ryan, K. A., Ruef, M. B., \& Doolabh, A. (1999). Positive behavior support for people with 
developmental disabilities: A research synthesis. Washington, DC: American Association on Mental Retardation. (ERIC Document Reproduction Service No. ED 439 580)

Chapman, D., \& Hofweber, C. (2000). Effective behavior support in British Columbia. Journal of Positive Behavior Interventions, 2, 235-237.

Clark, H. B., \& Hieneman, M. (1999). Comparing the wraparound process to positive behavioral support: What we can learn. Journal of Positive Behavior Interventions, 1(3), 183-186.

Clark, H. B., Lee, B., Prange, M. E., \& McDonald, B. A. (1996). Children lost within the childcare system: Can wraparound service strategies improve placement outcomes? Journal of Child and Family Studies, 5, 3954.

Dryfoos, J. G. (1996). Full-service schools. Educational Leadership, 57(3), 18-23.

Dunlap, D., \& Morelli-Robbins, M. (1990). A guide for reducing situation-specific behavior problems with task intersperse (Field Test Draft). Tampa: University of South Florida, Florida Mental Health Institute.

Durand, V. W, \& Crimmins, D, B. (1988). Identifying the variables maintaining self-injurious behavior. Journal of Autism and Developmental Disorders, 18, 99-107.

Eber, L., Nelson, C. M., \& Miles, P. (1997). Schoolbased wraparound for students with emotional and behavioral challenges. Exceptional Children, 63, 539555 .

Edmonson, H. (2000). A study of the process of the implementation of school reform in an urban middle school using positive behavioral supports: Not one more thing. Unpublished doctoral dissertation, University of Kansas, Lawrence.

Evans, M., Armstrong, M., \& Kuppinger, A. (1996). Family-centered intensive case management: A step toward understanding individualized care. Journal of Child and Family Studies, 5(1), 55-65.

Gardner, J. F., \& Nudler, S. (1999). Quality performance in human services: Leadership, values, and vision. Baltimore: Brookes.*

Giangreco, M. F., Cloninger, C. J., \& Iverson, V. S. (1998). Choosing outcomes and accommodations for children: A guide to educational planning for students with disabilities (2nd ed.). Baltimore: Brookes.*

Gray, C., \& Garand, J. D. (1993). Social stories: Improving responses of students with autism with accurate social information. Focus on Autistic Behavior, $8(1), 1-10$.

Hindron, D. S., Doser, D. A., McCammon, S. L., \& Powell, J. Y (1998). "A wraparound"-the wave of the future: Theoretical and professional practice implications for children and families with complex needs. Journal of Family Nursing 4(1), 6586.
Hawken, L. S., \& Horner, R. A. (2001). Evaluation ofa targeted group intervention within a schoolwide system of behavior support. Manuscript submitted for publication.

Horner, R. H. (2000). Positive behavior supports. Focus on Autism and Other Developmental Disabilities, 15(2), 97-105.

Horner, R. H., \& Carr, E. G. (1997). Behavioral support for students with severe disabilities: Functional assessment and comprehensive intervention. The Journal of Special Education, 31(1), 84-104.

Horner, R. H., Sugai, G., Lewis-Palmer, T., \& Todd, A. W. (2001). Teaching schoolwide behavioral expectations. Reports on Emotional and Behavioral Disorders in Youth, 1(4), 77-79, 93-96.

Horner, R. H., Sugai, G., Todd, A. W., \& Lewis Palmer, T. (1999-2000). Elements of behavior support plans: A technical brief. Exceptionality, 8(2); 205-215.

Individuals with Disabilities Education Act, 20 U.S.C. 1400-1497 (1999).

Kansas Kids Count (2000). Website, data on Wyandotte County, retrieved June 8, 2000 from URL. www.socwel.ukans.edu/kidcount (ERIC Document Reproduction Service No. ED 442 587)

Kartub, D. T., Taylor-Greene, S., March, R. E. \& Horner, R. H. (2000). Reducing hallway noise: A systems approach. Journal of Positive Behavior Intervention, 2(3), 179-182.

Kincaid, D. (1996). Person-centered planning. In L. K. Koegel, R. L. Koegel, \& G. Dunlap (Eds.), Positive behavioral support. Including people with difficult behavior in the community (pp. 439-466). Baltimore: Brookes.*

Lane, K. L., Umbreit, J., \& Beebe-Frankenberger, M. E. (1999). Functional assessment research on students with or at risk for EBD: 1990 to the present. Journal of Positive Behavioral Interventions, 1(2), 101-111.

Lawson, H. A., \& Sailor, W. (2000). Integrating services, collaborating, and developing connections with schools. Focus on Exceptional Children, 33(2), 1-22.

Lewis, T. J., \& Sugai, G. (1999). Effective behavior, support: A systems approach to proactive schoolwide management. Focus on Exceptional Children, 31(6), 124.

Lewis, T J., \& Sugai, G. (1999). Safe schools Schoolwide discipline practices. (Miniseries Monograph). International Conference for Council for Children with Behavior Disorders.* 
Liaupsin, C. J., Scott, T. M., \& Nelson, C. M. (2Q00). Functional behavioral assessment: An interactive tutorial. Longmont, CO: Sopris West.*

Lohrmann-O'Rourke, S., Knoster, T., Sabatine, K., Smith, D., Harvath, B., \& Llewellyn, G. (2000). School-wide application of PBS in the Bangor area school district. Journal of Positive Behavior Interventions, 2,238-240.

March, R., Horner, R. H., Lewis-Palmer, T., Brown, D., Crone, D. A., \& Todd, A. W (1999). Functional assessment checklist for teachers and staff. Eugene, OR: Author.

Nakasato, J. (2000). Data-based decision making in Hawaii's behavior support effort. Journal of Positive Behavior Interventions, 2, 247-251.

Nelson, J. R., Martella, R, \& Galand, B. (1998). The effects of teaching school expectations and establishing consistent consequences on formal office disciplinary actions. Journal of Emotional and Behavioral Disorders, 60), 153-161.

O'Neill, R. E., Horner, R. H., Albin, R. W, Sprague, J. R., Storey, K., \& Newton, J. S. (1997). Functional assessment for problem behavior: A practical handbook, (2nd ed.). Pacific Grove, CA: Brooks/Cole Publishing.*

Park, J., Turnbull, A. P., \& Turnbull, H. R. (2002). Impacts of poverty on quality of life in families of children with disabilities. Exceptional Children, 68, 151-170.

Reid, D. H. (2000). Enhancing the applied utility of functional assessment. The Journal of the Association for Persons with Severe Handicaps, 25, 241-244.

Ruef, M. B., \& Turnbull, A. P. (in press). Stakeholder opinions on accessible informational products helpful in building positive, practical solutions to behavioral challenges of people with mental retardation and/or autism. Education and Training in Mental Retardation and Developmental Disabilities.

Sadler, C. (2000). Effective behavior support implementation at the district level: Tigard-Tualatin school district. Journal of Positive Behavior Interventions, 2, 241-243

Safe and Drug-Free Schools and Communities Act of 1994, Pub. L. No. 103-382, 4001-4133, 108 Stat. 3518 (codified as amended at 20 U.S.C. 7101-7143 [20001).

Sailor, W (2002). Inclusive education and school/community partnerships. New York: Teachers College Press.*

Sailor, W, Freeman, R., Britten, J., McCart, A., Smith, C., Scott, T., \& Nelson, M. (1999-2000). Using information technology to prepare personnel to implement functional behavioral assessment and positive behavioral support. Exceptionality, 8, 217-230.
Schalock, R. L. (2000). Three decades of quality of life. In M. Wehmeyer \& J. Patton (Eds.), Mental retardation in the 21 st century (pp. 335-356). Austin, TX: PROED.*

Sherman, A. (1997). Poverty matters. Washington, DC: Children's Defense Fund. (ERIC Document Reproduction Service No. ED 417 867)

Sugai, G., \& Horner, R. (2001).. School climate and discipline: Going to scale. Paper presented at the National Summit on the shared implementation of IDEA. Retrieved November 8, 2001, from http://www.pbis.org

Sugai, G., Horner, R. H., Dunlap, G., Hieneinan, M., Lewis, T., Nelson, C., Scott, T., Liaupsin, C., Sailor, W, Turnbull, A. P., Turnbull, H. R., Wickham, D., Ruef, M., \& Wilcox, B. (2000). Applying positive behavioral support and functional behavior assessment in the schools. Journal of Positive Behavior Interventions, 2(3), 131143.

Sugai, G., Hornet, R. H., \& Gresham, F. M. (in press). Behaviorally effective school environments. In M. R. Shinn, G. Stoner, \& H. M. Walker (Eds.) Interventions for academic and behavior problems: Preventive and remedial approaches. Silver Spring, MD: National Association of School Psychologists.

Sugai, G., Lewis-Palmer, T, \& Hagan-Burke, S. (19992000). Overview of the functional behavioral assessment process. Exceptionality, 8(3), 149-160.

Taylor-Greene, S., Brown, D., Nelson, L., Longton, J., Gassman, T., Cohen, J., Swartz, J., Horner, R. H., Sugai, G., \& Hall, S. (1997). School-wide behavioral support: Starting the year off right. Journal of Behavioral Education, 7,99-112.

Taylor-Greene, S., \& Kartub, D. T. (2000). Durable implementation of schoolwide behavior support: The high five program. Journal of Positive Behavior Interventions, 2, 233-235.

Todd, A. W, Horner, R. H., Sugai, G., \& Colvin, G. (1999). Individualizing schoolwide discipline for students with chronic problem behaviors: A team approach. Effective School Practices, 17(4), 72-82.

Todd, A.. W, Horner, R. H., Sugai, G., \& Sprague, J. R. (1999). Effective behavior support: Strengthening schoolwide systems through a team-based approach. Effective School Practices, 17(4), 23-27.

Touchette, P. E., MacDonald, R. F., \& Langer, S. M. (1985). A scatter plot for identifying stimulus control of problem behavior. Journal of Applied Behavior Analysis, 18,343351 .

Turnbull,. A. P, \& Turnbull, H. R. (1999). Comprehensive lifestyle support for adults with challenging behavior: From rhetoric to reality. Education and Training 
in Mental Retardation and Developmental Disabilities, 34,373-394.

Turnbull, A. P., Turnbull, H. R., Poston, D., Beegle, G., Blue-Banning, M., Diehl, K., Frankland, C., Mische Lawson, L., Lord, L., Marquis, J., Park, J., Stowe, M., \& Summers, J. A. (2000). Enhancing quality of life of families of children and youth with disabilities in the United States. Lawrence, KS: Beach Center on Families and Disabilities.

Turnbull, H. R., Wilcox, B. L., Stowe, E., \& Turnbull, A. P. (2001). IDEA requirements for use of PBS: Guidelines for responsible agencies. Journal of Positive Behavior Support, 3(1), 11-18

Turnbull, H. R., Wilcox, B. L., Turnbull, A. P., Sailor, W, \& Wickham, D. (2001). IDEA, positive behavioral supports, and school safety. Journal of Law and Education, 30, 445-503.

U.S. Department of Education (1992). To assure the free appropriate public education of all children with disabilities: Fourteenth annual report to Congress on the implementation of the Individual with Disabilities Education Act, Section 618. Washington, DC: Author. (ERIC Document Reproduction Service No. ED 347 779)

United States General Accounting Office (2000). Atrisk youth: School-community collaboration focused on improving. Author: Washington, DC. (ERIC Document Reproduction Service No. ED 447 239)

VanDenBurg, J. E., \& Grealish, E. M. (1996). Individualized services and supports through the wraparound process: Philosophy and procedures. Journal of Child and Family Studies, 5, 7-22.

Warren, J. S., Edmonson, H. M., Griggs, P., Lassen, S., McCart, A., Turnbull, A., \& Sailor, W. (in press-a) Urban applications of school-wide positive behavior support: Critical issues and lessons learned. Journal of Positive Behavior and Intervention.

Varren, J. S., Edmonson, H. M., Turnbull, A. P., Sailor, W, Wickham, D., Griggs, P, \& Beech, S. (in pressb). School-wide application of positive behavioral supports: Implementation and preliminary evaluation of PBS in an urban middle school. Educational Psychology Reviews.

Weigle, K. L. (1997). Positive behavior support as a model for promoting educational inclusion. journal of the Association for Persons with Severe Handicaps, 22(1), 36-48.

Wilcox, B. L., Turnbull, H. R., \& Turnbull, A. P. (1999-2000). Behavioral issues and IDEA: Positive behavioral interventions and supports and the functional behavioral assessment in the disciplinary context. Exceptionality, 8(3), 172-187.
Yin, R. K. (1994). Case study research: Design and methods (2nd ed.). Thousand Oaks, CA: Sage.*

\section{ABOUT THE AUTHORS} ANN TURNBULL (CEC \#665); HANK ED-
MONSON AND PETER GRIGGS (CEC MS Federation); DONNA WICKHAM (CEC \#665); WAYNE SAILOR, RACHEL FREEMAN, DOUG GUESS, STEVE LASSEN, AMY MCCART, AND JIYEON PARK (CEC \#665); LAURA RIFFEL (CEC \#197); RUD TURNBULL (CEC \#665); AND JARED WARREN, Researchers, Beach Center on Disability, The University of Kansas, Lawrence.

Correspondence concerning this article should be addressed to Ann Turnbull, Beach Center on Dis ability, The University of Kansas, Haworth Hall, Room 3136, 1200 Sunnyside Avenue, Lawrence, KS 66045-7534.

The authors wish to acknowledge the helpful contributions of Shelly Beech, Nancy Hale, Denise Smerchek, and Brennan Wilcox.

Manuscript received May 2001; accepted November 2001 .

\section{BOOKS NOW}

*To order books referenced in this journal, please call 24 hrs/365 days: 1-800-BOOKS-NOW (2665766); or 1-732-728-1040; or visit them on the Web at

http://www.BooksNow.com/ExceptionalChildr htm. Use Visa, M/C, AMEX, Discover, or send check or money order $+\$ 4.95 \mathrm{~S} \& \mathrm{H}(\$ 2.50$ each add'l item) to: Clicksmart, 400 Morris Avenue, Long Branch, NJ 07740; $1-732728-1040$ or FAX 1-732- 728-7080.

This research was supported by a grant from the National Institute on Disability and Rehabilitation Research to the Beach Center on Disability, Grant \#H133B980050. 